\title{
Lipase-catalyzed transesterification of medium-Iong-medium structured lipid (MLM-SL) using palm olein and tricaprylin in packed-bed Reactor (PBR)
}

\author{
Qabul Dinanta Utama1, Azis Boing Sitanggang ${ }^{1,2}$, Dede Robiatul Adawiyah ${ }^{1,2 *}$, Purwiyatno Hariyadi ${ }^{1,2}$ \\ ${ }^{1}$ Department of Food Science and Technology, Faculty of Agricultural Engineering and Technology, IPB University, IPB Darmaga Campus \\ 16680, Bogor, Indonesia, ${ }^{2}$ Southeast Asian Food and Agricultural Science and Technology (SEAFAST) Center, IPB University, IPB Darmaga \\ Campus 16680, Bogor, Indonesia
}

\section{A B S T R A C T}

\begin{abstract}
Lipase-catalyzed transesterification between refined bleached deodorized palm olein (RBDO) and tricaprylin to produce medium-longmedium structured lipid (MLM-SL) in a packed bed reactor (PBR) has been investigated. A specific sn-1,3 commercial Lipozyme TL IM was used as biocatalyst. Within this study, the progress of transesterification was monitored especially for triacylglycerol (TAG) formation with equivalent carbon number (ECN) of 32, presumably 1,3-dicapryoyl-2-oleoyl-sn-glycerol (COC). Transesterification conditions investigated were residence times (i.e., 15, 30, and $60 \mathrm{~min}$ ) and enzyme loadings (2.0 and $4.5 \mathrm{~g})$. The highest yield of ECN 32 (13\%) and transesterification degree $(71 \%)$ were obtained at residence time of 15 mins for both enzyme loadings. Longer residence time seemed to facilitate lipid hydrolysis over transesterification. This was indicated by the number of peaks appearing in the high-performance liquid chromatography (HPLC) chromatograms and the reduction of fat slip melting point (SMP). Additionally, the highest productivity was obtained at $2.0 \mathrm{~g}$ enzyme loading. Conclusively, this study has demonstrated the potential use of packed-bed reactor with immobilized Lipozyme TL IM for continuous synthesis of MLM-SLs especially TAG with ECN32.
\end{abstract}

Keywords: 1,3-dicapryoyl-2-oleoyl-sn-glycerol; Lipase; Palm olein; Packed bed reactor; Structured lipids

\section{INTRODUCTION}

Medium-long-medium structured lipid (MLM-SL) is a typical structured lipid that contains medium chain fatty acids (MCFAs, C6-C12) at sn-1,3 positions and long chain fatty acid (LCFA, C14-C24) at sn-2 position. The presences of MCFA and LCFA on a triacylglycerol (TAG) molecule poses benefits especially for clinical nutrition purposes such as to improve fat malabsorption and managing obesity. MCFAs at $s n-1,3$ positions are directly transported to liver as instant energy sources. In addition to this, structured lipid where LCFA is at $s n-2$ position is also directly absorbed. MLM-SLs are not commonly found from natural resources. Both chemical and enzymatic synthesis are used in an attempt to produce MLM-SLs. The enzymatic interesterification was preferably to synthesize MLM-SL due to its selectivity, less by-products produced, mild reaction conditions, and ease of biocatalysts recovery.
Herein, enzyme-based MLM-SL synthesis has gained popularity in recent years (Utama et al., 2019).

The continuous synthesis of MLM-SL was of importance especially at industrial scale. Continuous synthesis leads to the reduction of unproductive times (due to start-, and end-procedures in repetitive batch cycles), and also minimization of batch-to-batch oscillation in product quality (Sitanggang et al., 2016, 2015, 2014a). Generally, MLM-SL synthesis in continuous system was conducted using packed bed reactor (PBR), micro-channels (MC), enzymatic membrane reactor (EMR). PBR has several advantages such as ease of operation, better product control, and high reaction rate and mass transfer (Itabaiana et al., 2013; Silva et al., 2011). In PBR system, flow rate or residence time plays important role for reaction kinetics and thus, volumetric productivity. The operation of PBR requires the enzyme to be immobilized. Herein, another

\footnotetext{
*Corresponding author:

Dede Robiatul Adawiyah, Department of Food Science and Technology, Faculty of Agricultural Engineering and Technology, IPB University, IPB Darmaga Campus 16680, Bogor, Indonesia, Southeast Asian Food and Agricultural Science and Technology (SEAFAST) Center, IPB University, IPB Darmaga Campus 16680, Bogor, Indonesia E-mail: dede_adawiyah@apps.ipb.ac.id

Received: 11 April 2020; Accepted: 29 October 2020
} 
consideration for successful and efficient MLM-SL synthesis in PBR is the cost of biocatalyst. Lipozyme TL IM (Novozymes A/S) is an $s n-1,3$ specific lipase originating from Thermomyces lanuginosus, and immobilized in a non-compressible silica gel carrier (Yang et al., 2014). It has been reported for its economically low price and larger active side pockets possible for rapid catalysis of lipid transesterification (Basri et al., 2013; Wang et al., 2008). For MLM-SL synthesis, Lipozyme TL IM showed higher operational stability in transesterification reaction as compared to that of acidolysis reaction (Utama et al., 2020).

Refined bleached deodorized palm olein (RBDO) is always considered as a potent substrate to produce MLM-SL. It is due to high content of oleic acid at $s n-2$ position (May and Nesaretnam, 2014). The consumption of oleic acid has shown positive effect for the prevention of cardiovascular diseases (Mele et al., 2018; Ong and Goh, 2002). In addition to this, caprylic acid has been shown to be more effective to increase plasma ketone for rapid energy sources as compared to other MCFAs (Vandenberghe et al., 2017). The incorporation of caprylic acid into RBDO is expected to yield MLM-SL with equivalent carbon number $(\mathrm{ECN})$ of 32, presumably1,3-dicapryoyl-2-oleoyl-sn-glycerol (COC). In our previous work (Utama et al., 2020), we reported the transesterification of RBDO and tricaprylin in batch system that could obtain 16.75\% MLM-SL with ECN 32. In addition, Lai et al. (2005) reported that acidolysis reaction between RBDO with caprylic acid in PBR system catalyzed by Lipozyme IM 60 produced $35.3 \%$ of ECN 32 . However, studies about MLM-SL synthesis using RBDO and tricaprylin in PBR system are limited. Based on this rationale, this study was aimed to synthesize MLM-SL using RBDO and tricaprylin under PBR system. The synthesis was catalyzed by Lipozyme TL IM. The effect of residence time and enzyme loading were also investigated within this work.

\section{MATERIALS AND METHODS}

\section{Materials}

RBDO with iodine value (IV) of 60 was obtained from PT. Salim Ivomas TBK, Indonesia. Tricaprylin, molecular sieve $4 \AA$ and triglyceride standard mixture (tricaprin, tricaprylin, trilaurin, trimyristin, and tripalmitin) were purchased from Sigma-Aldrich, Singapore. Lipozyme TL IM was obtained from Novozyme A/S, Denmark. Hexane, chloroform, ethanol, octanol, sodium hydroxide, acetonitrile, and acetone were analytical grade and purchased from Merck, Germany.

\section{Synthesis of MLM-SL in continuous system (packed bed reactor)}

The schematic design of PBR system is shown in Fig. 1. The reactor system was consisted of substrate reservoir,

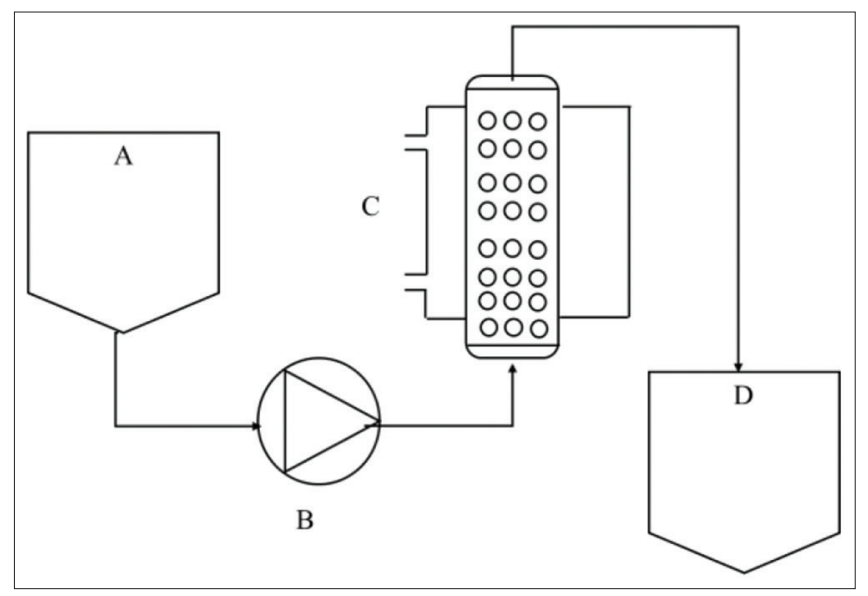

Fig 1. Schematic design of reactor system: (A) sample reservoir, (B) peristaltic pump, (C) packed bed reactor, and (D) product reservoir.

peristaltic pump (BT 100-IF longer Peristaltic Pump, Baoding longer Precision Pump Co., Ltd), column, water bath (Stephen Hacke, Germany), and product reservoir. Packed bed reactor column (ID $=11 \mathrm{~mm}$ and $\mathrm{H}=80$ $\mathrm{mm}$ ) with jacketed wall was made from glass material. The upper and lower ends of column were equipped with filter which was impermeable for the biocatalyst resins. The column was packed with either 2.0 or $4.5 \mathrm{~g}$ of biocatalysts. For $2.0 \mathrm{~g}$ of enzyme loading, molecular sieve $4 \AA$ (Sigma-Aldrich) was used as "dummy enzyme" to avoid catalysts floating within the column. The mixture of substrates (RBDO and tricaprylin with molar ratio of $1: 1$ ) was pumped into the reactor from the upper-end of the column. Three different residence times were realized (i.e., 15, 30, and $60 \mathrm{~min}$ ) within this study. The residence time was calculated according to Levenspiel (1999) and Sitanggang et al. (2014b) as follows (eq. 1).

$$
\tau=\frac{\mathrm{V}}{\mathrm{v}_{0}}
$$

where $=$ residence time $(\mathrm{s})$, = working volume of the reactor $\left(\mathrm{m}^{3}\right)$ and $=$ volumetric flow rate $\left(\mathrm{m}^{3} / \mathrm{s}\right)$. The temperature of reaction $\left(50^{\circ} \mathrm{C}\right)$ was maintained by circulating water continuously into substrates reservoir and jacketed column of PBR. Samples were taken from product reservoir after $3 \mathrm{~h}$ of reaction (without recycle procedure). Productivity of MLM-SL synthesis especially for ECN32 was calculated as follows:

$$
\mathrm{P}=\mathrm{PA}\left\{\frac{\left(\frac{\mathrm{V}}{\tau}\right)}{\left[\mathrm{E}_{0}\right]}\right\}
$$


Where $=$ productivity $\left(\frac{\mathrm{m}^{3}{ }_{\mathrm{ECN} 32}}{\mathrm{~g}_{[\mathrm{E}]} \times \mathrm{h}}\right), \mathrm{PA}=$ percentage area of ECN32 and $\left[\mathrm{E}_{0}\right]=$ enzyme weight (i.e., 2.0 or $4.5 \mathrm{~g}$ ).

\section{TAG composition analysis}

TAG composition analysis was conducted according to Utama et al. (2020). The TAG peaks were identified using TAG mixture standard peaks and $\mathrm{ECN}$ value. ECN can be obtained as $\mathrm{CN}-2(\mathrm{DB})$, where $\mathrm{CN}$ shows the total amount of carbon in the TAG molecule without glycerol, and DB is number of double bonds on the TAG molecule (Holčapek et al., 2005). The change of tricaprylin concentration before and after interesterification was used to determine transesterification degree (TD) and as follows (eq. 3):

$$
\mathrm{TD}=\frac{\left(P_{E}-P_{O}\right)}{P_{O}}
$$

where $\mathrm{P}_{\mathrm{O}}$ and $\mathrm{P}_{\mathrm{E}}$ were percentage area of tricapylin prior to- and after reaction, respectively.

\section{Determination of acylglycerol fractions}

The acylglycerol fractions were determined by AOCS Official Method Cd 11b-91 (AOCS, 2017) with minor modifications. The acylglycerol fractions were analyzed using a Hewlett Packed Series 6890 autoinjector gas chromatography system equipped with a flame ionization detector (FID) and DB-5HT column $(\mathrm{L}=15 \mathrm{~m}$, $\mathrm{ID}=320 \mathrm{~nm}$, and thickness $=0.1 \mu \mathrm{m}$ ).

\section{Differential scanning calorimetry}

Melting and crystallization point of blending and the produced structured lipids were determined using differential scanning calorimetry (DSC) (model TA-60, TA instrument, New Castle) according to Saberi et al. (2011). The crystallization was indicated by peaks in cooling curves, whereas melting points were indicated by heating curves.

\section{Slip melting point (SMP)}

Slip melting point (SMP) was determined according AOCS Official method Cc 3-25 (AOCS, 2017b). The measurements were run in triplicate and reported as a mean \pm standard deviation (SD).

\section{Statistical analysis}

Data are presented as mean \pm standard deviation. The effects of different treatments (i.e., residence time and enzyme loading) on the observed parameters were analyzed by one-way analysis of variance (ANOVA) and followed by Duncan posthoc test using IBM SPSS 20 software.

\section{RESULTS AND DISCUSSION}

\section{TAG compositions of structured lipids}

The formation of MLM-SL was determined by comparing peaks (i.e., TAG composition) between TAG mixture standard and transesterification products. In the blended mixture (i.e., RBDO:tricaprylin (1:1)), the dominant TAGs were mainly those with ECN $>42$. TAGs of blended mixture were dominated by tricaprylin (CCC), palmiticoleic-oleic (POO), palmitic-oleic-palmitic (POP), and palmitic-linoleic-oleic (PLO). After transesterification reaction, these TAGs reduced, leading to the emergences of several new TAG species especially with ECN 32, 38, and 40 (see Fig. 2b-d). This change was presumed as the results of caprylic acid incorporation (mono- or di-substitution) within TAG molecules found in RBDO. During batch transesterification using the same substrates and biocatalyst, several new TAG species were also produced including ECN 30, 32, 34, 36, 38, 40, and 42 (Utama et al., 2020). Moreover, ECN 32 also showed highest TAG concentration among other TAG species in batch-wise. Within this work, the incorporation of caprylic acid into RBDO catalyzed by Lipozyme TL IM also showed higher possibility to produce COC which is indicated by higher chromatogram areas of ECN 32 as compared to that of blended mixture's peak area (Fig. 2a-d). Herein, COC was selected as TAG of interest and to represent MLM-SL in this study.

In continuous reaction, residence time plays a key role to determine the rate of disappearance or formation of chemical species of interest. In this study, $15 \mathrm{~min}$ of residence time was considered as the optimum residence time for both enzyme loadings due to high concentrations of ECN 32 (Fig. 3). The increase in residence time had no influence on the concentration of TAG dominant. Yang et al. (2014) reported a range of residence time of 30-40 min as optimum condition to produce MLMSL using soybean oil medium chain triacylglycerol (MCT) catalyzed by Lipozyme TL IM in PBR system. In addition, $\mathrm{Xu}$ et al. (2002) also reported that Lipozyme TL IMcatalyzed interesterification between fish oil and MCT in PBR system showed the degree of reaction reached equilibrium at 30-40 min of residence times.

In general, the increase in enzyme concentration in reacting medium leads to the increased reaction rate. Zhang et al. (2001) reported that interesterification degree was positively influenced by the enzyme loading and reached equilibrium at $6 \%$ of enzyme loading. However, within this work, two levels of enzyme loading (i.e., 2.0 and $4.5 \mathrm{~g}$ ) had no effect on the product concentration obtained. The results for different enzyme loadings also showed similar patterns 


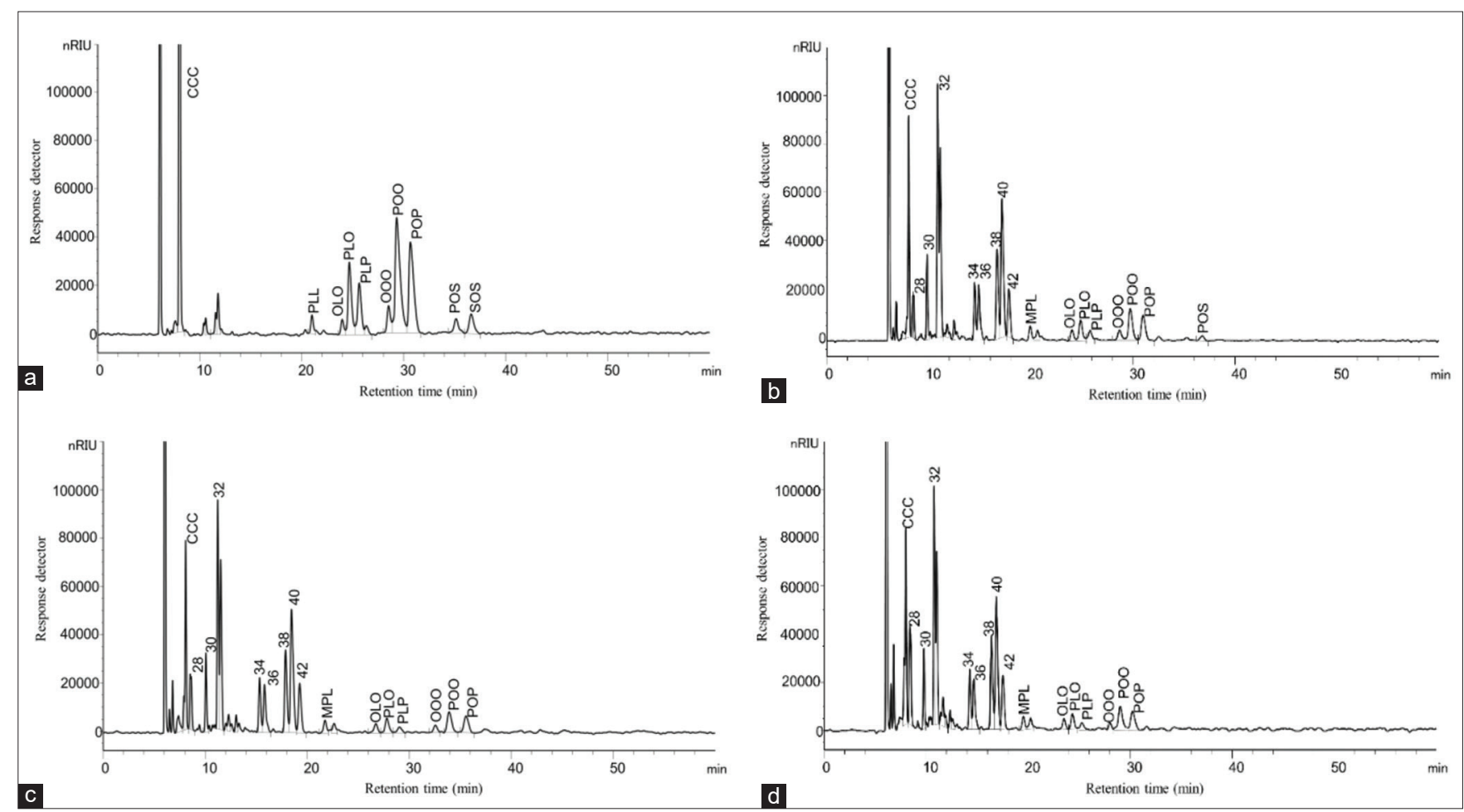

Fig 2. Chromatograms of (a) blending RBDO : tricaprylin (1:1), (b) $\tau=15 \mathrm{~min}$, (c) $\tau=30 \mathrm{~min}$, and (d) $\tau=60$ min with enzyme loading of $4.5 \mathrm{~g}$ and temperature of $50^{\circ} \mathrm{C}$. TC/CCC = tricaprylin; $\mathrm{MPL}=$ myristic-palmitic-linoleic; OLO = oleic-linoleic-oleic; $\mathrm{PLO}=$ palmitic-linoleic-oleic; $\mathrm{PLP}=$ palmiticlinoleic-palmitic; $\mathrm{OOO}$ = oleic-oleic-oleic; $\mathrm{POO}=$ palmitic-oleic-oleic; $\mathrm{POP}=$ palmitic-oleic-palmitic.

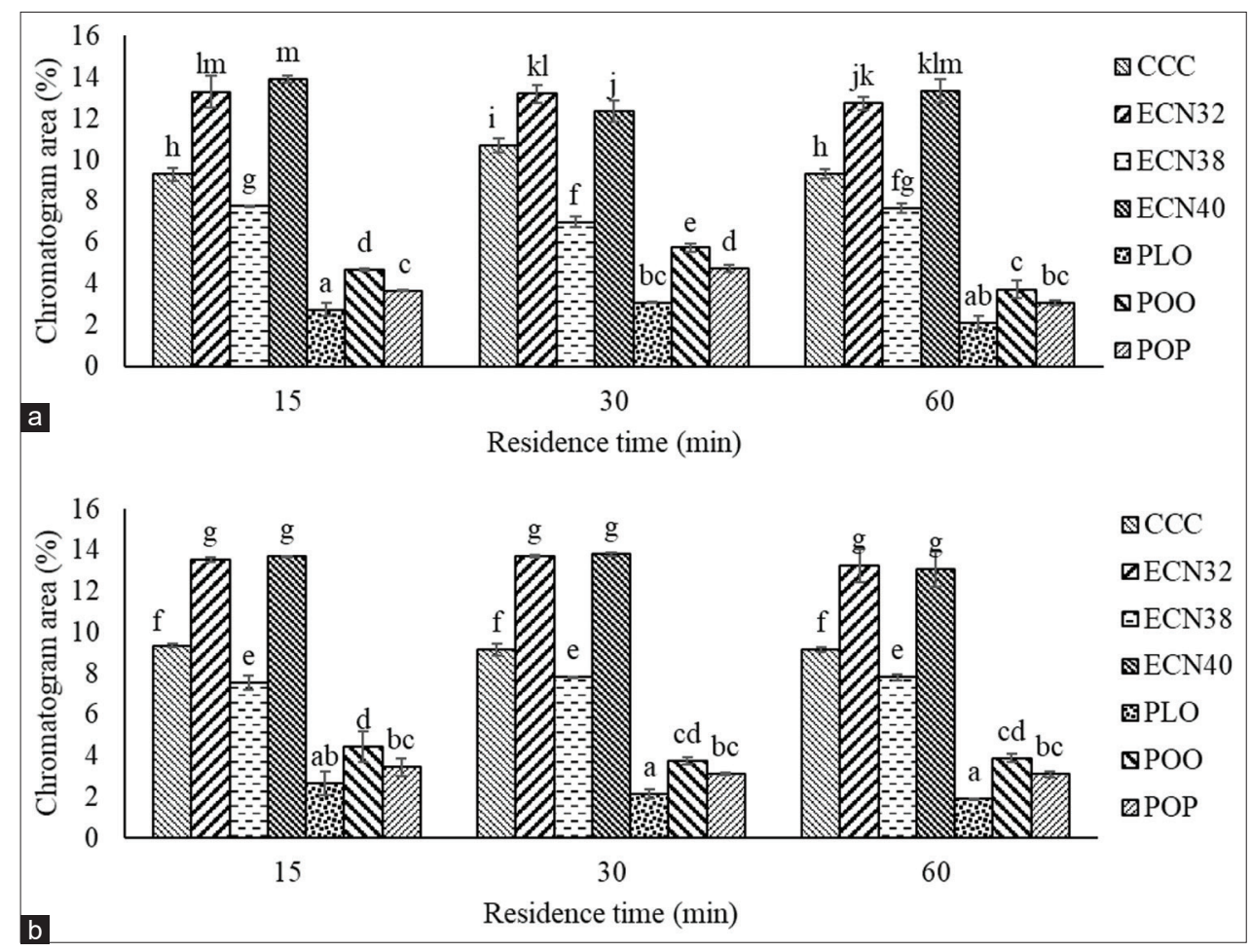

Fig 3. Effect of residence time $(\tau)$ on the TAG profiles of the structured lipids. Enzyme loading of $2.0 \mathrm{~g}(\mathrm{a})$, and $4.5 \mathrm{~g}$ (b). Different letters indicate a significant difference $(p<0.05)$.

especially for the reduction trend of initial dominant TAGs and the increase trend of new TAGs (Fig. 3). Two enzyme loadings employed within this study might be presumably excessive. This could be indicated by relatively short reaction times to reach concentration plateau for both enzyme loadings (i.e., approximately $15 \mathrm{~min}$, see Fig. 4). 


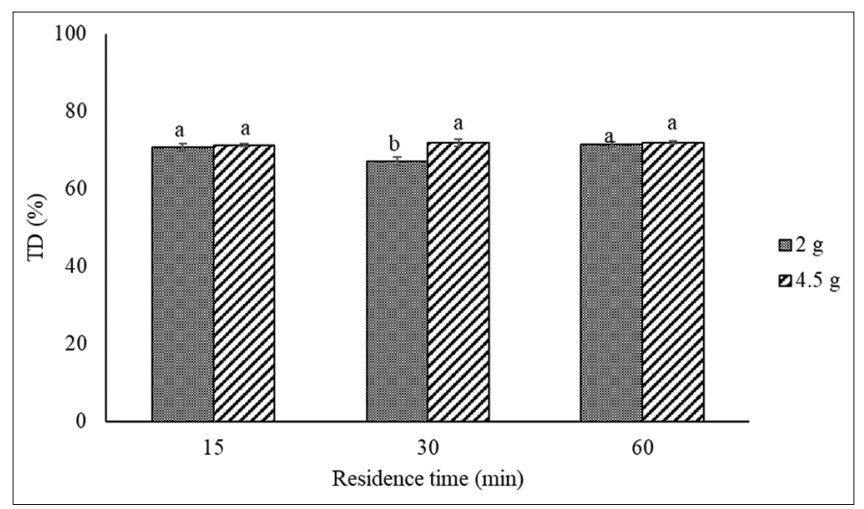

Fig 4. Effect of residence time $(\tau)$ on transesterification degree (TD). Different letters indicate a significant difference $(p<0.05)$.

\section{Productivity of structured lipid (ECN 32) synthesis}

For optimum residence time (i.e., $\tau=15 \mathrm{~min}$ ), enzyme loading $\left(\mathrm{E}_{0}\right)$ of $2.0 \mathrm{~g}$ had volumetric flow rate $\left(\mathrm{v}_{0}\right)$ of 4.33 $\times 10^{-9} \mathrm{~m}^{3} / \mathrm{s}$. Assuming the density of the reactor did not change throughout the reaction time and the percentage area of ECN 32 was $13.84 \%$ (see Fig. 3), the calculated productivity was about $3.33 \times 10^{-10} \mathrm{~m}^{3} / \mathrm{g}_{[\mathrm{E}]}$ s. For enzyme loading $\left(\mathrm{E}_{0}\right)$ of $4.5 \mathrm{~g}$, the optimum residence time was also the same with $\left(\mathrm{E}_{0}\right)$ of $2 \mathrm{~g}$. However, the volumetric flow rate was raised to $6.5 \times 10^{-9} \mathrm{~m}^{3} / \mathrm{s}$. Hence, with percentage area of ECN 32 of $13.55 \%$, the calculated productivity based on eq. (2) was $1.67 \times 10^{-10} \mathrm{~m}^{3} / \mathrm{g}_{[\mathrm{E}]} \mathrm{s}$. Based on the productivity value, enzyme loading $2.0 \mathrm{~g}$ was considered as the optimum condition.

\section{Acylglycerol fraction after transesterification}

Despite of its small amount is required (i.e., microaqueous system), water still has important role during lipase-catalyzed interesterification. In lipase-catalyzed interesterification reaction, water was included in the enzyme materials or substrates. High content of water in system will shift the progress of reaction towards hydrolysis. Herein, the formations of new TAGs in transesterification are accompanied by the formations of by-products such as diacylglycerol (DAG), monoacylglycerol (MAG) and the fatty acid (FA) in reaction system. Kadhum and Shamma (2017) determined the formation acyl glycerol complexes as results of lipase-catalyzed interesterification. Moreover, Hermansyah et al. (2010) reported that hydrolysis of triacylglycerol by the enzyme was a stepwise process in order to obtain DAG, MAG, and glycerol in which enzyme-substrate complexes and FA are formed at each reaction step.

For blending product, acyl glycerol fraction only consisted of TAGs and DAGs. After transesterification reaction, changes on acylglycerol fractions were observed (Fig. 5). Within 15 min of residence time, TAG concentration slightly increased while DAG concentration decreased. In
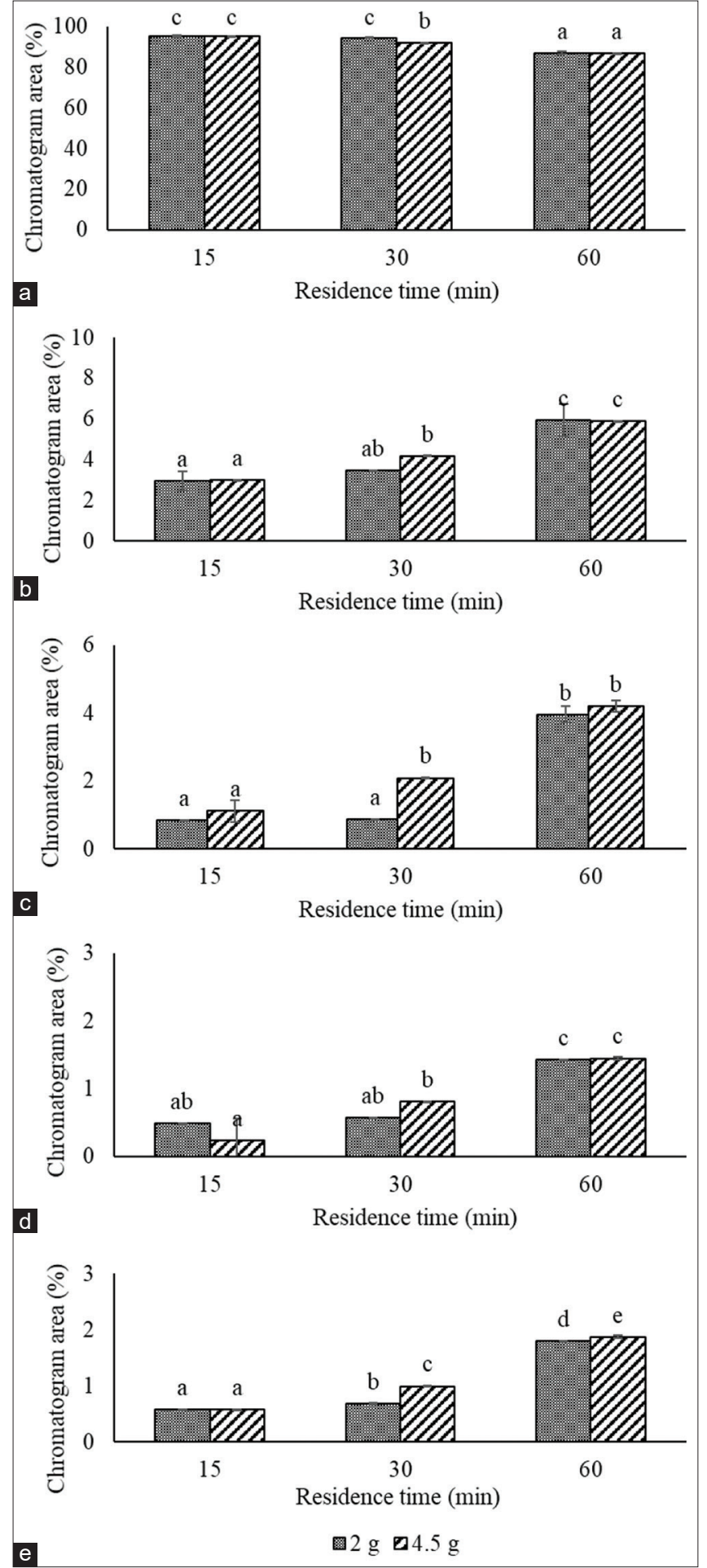

Fig 5. Effect of residence time and enzyme loading on (a) TAG, (b) DAG, (c) MAG, (d) fatty acid, and (e) glycerol concentration of structured lipid. Different letters indicate a significant difference $(p<0.05)$.

addition to this, MAG, glycerol, and FA were also detected during the reaction. Increased residence time (i.e., 30 and 60 min) enhanced DAG, MAG, glycerol, and FA formation. This might be due to facilitation of a longer contact time between the initial and produced TAGs with enzyme 
molecules that favored hydrolysis reaction. Higher amounts of side products from the transesterification might be detrimental especially for the separation of the produced structured lipids. In addition to this, formation of FA could lead to $\mathrm{pH}$ shift that levels off the stability of the enzyme.

Different enzyme loadings relatively showed similar concentrations of acylglycerol fractions. In contrast, Zhang et al. (2001) reported that the increase of enzyme loading had positive impact on the increased formation of FAs and DAGs. This was due to a higher amount of water from the enzyme materials involved during the reaction. Moreover, in higher enzyme loading, such higher active pockets were also available to perform hydrolysis on the TAGs.

\section{Thermal profile of structured lipid product}

The concentrations of MAGs and DAGs may influence melting point, crystal formation and/or temperature, and the hardness of lipids (Basso et al., 2010; Saberi et al., 2011). In this work, SMP of the transesterification product shifted in parallel to the changes in the compositions of acylglycerol fractions. Generally, the increasing of DAGs concentration will reduce slip melting point of lipid (Fig. 6). SMP of blending product was $4.33^{\circ} \mathrm{C}$. At $15 \mathrm{~min}$ of residence time, SMP was higher than at 30 and $60 \mathrm{~min}$. At $15 \mathrm{~min}$ of residence time, the formations of TAGs (also MLM TAG) were favored whereas for longer residence times the hydrolysis was pronounced. Thus, the concentrations of DAGs were higher than TAGs for these longer residence times (i.e., 30 and $60 \mathrm{~min}$ ). The effects of DAGs and MAGs concentration on SMP also depend on types of fatty acid (i.e., length of carbon chain, saturated or unsaturated) and isomeric positions of fatty acids. Siew (2002) reported that 1, 2 isomers of DAG was found to be more effective to reduce melting point as compared to that of 1,3 isomers of DAG. Moreover, Subroto et al. (2019) mentioned that higher concentrations of saturated fatty acids in DAG and MAG structures could increase melting point of lipids.

The information about melting and crystallization temperature of fats is important for designing their applications in food products. Within this study, transesterification was also found to reduce melting and crystallization point of blended product (Fig. 7 and Table 1). Furthermore, the obtained structured lipid showed a smaller range in melting temperatures and a wider range in crystallization temperatures as compared to that of

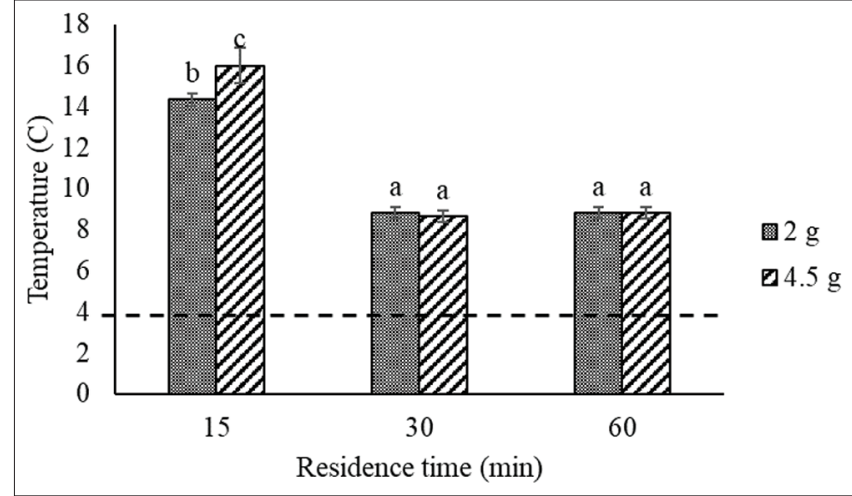

Fig 6. Slip melting point of blending product (dashed line) and structured lipid products. Different letters indicate a significant difference $(p<0.05)$.

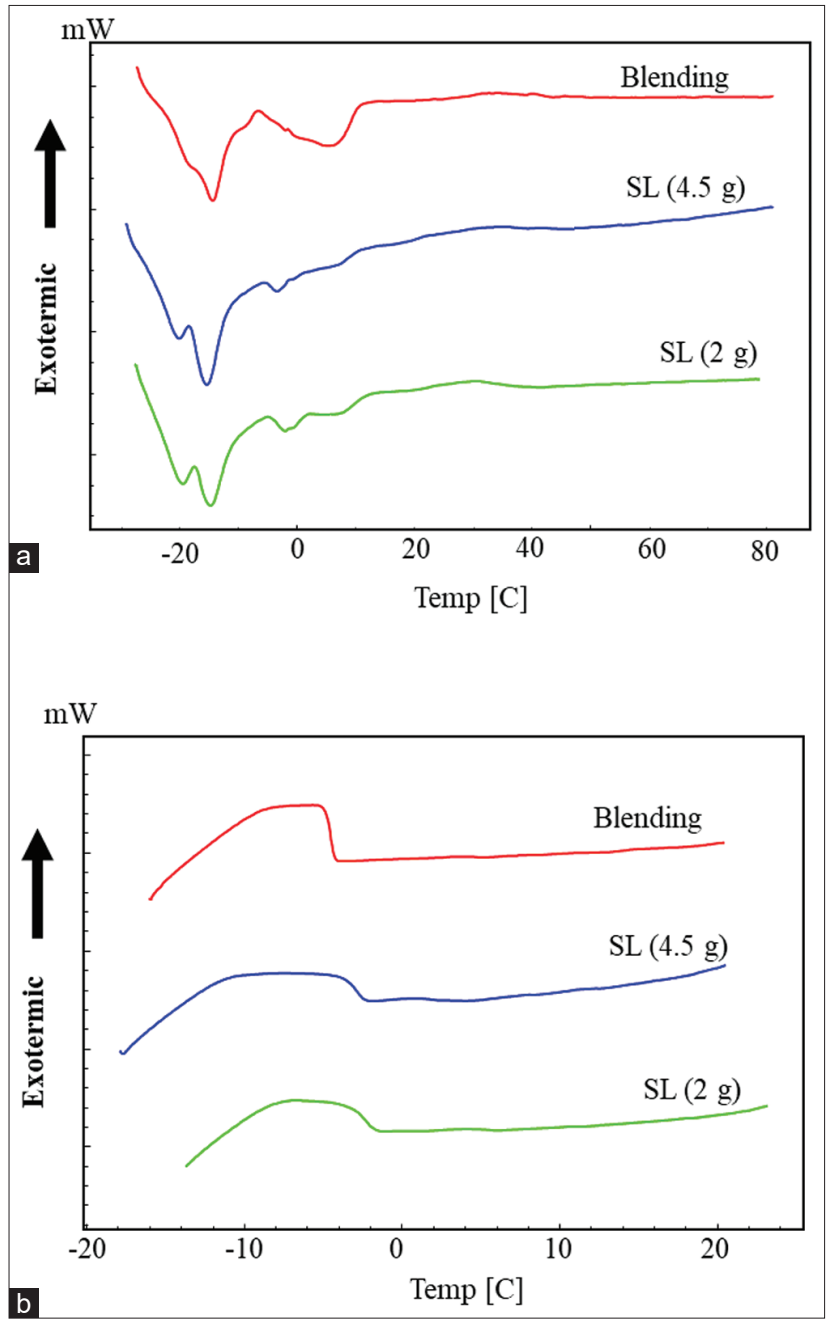

Fig 7. Differential scanning calorimetry (DSC) of melting (a) and crystallization (b) curve of blending and structured lipid products (SL).

Table 1: Thermal profiles of blending and structured lipid products

\begin{tabular}{|c|c|c|c|c|c|c|c|c|}
\hline \multirow[t]{2}{*}{ Sample } & \multicolumn{4}{|c|}{ Melting } & \multicolumn{4}{|c|}{ Crystallization } \\
\hline & Onset $\left({ }^{\circ} \mathrm{C}\right)$ & Peak $\left({ }^{\circ} \mathrm{C}\right)$ & Endset $\left({ }^{\circ} \mathrm{C}\right)$ & $\Delta \mathrm{h}(\mathrm{J} / \mathrm{g})$ & Onset $\left({ }^{\circ} \mathrm{C}\right)$ & Peak $\left({ }^{\circ} \mathrm{C}\right)$ & Endset $\left({ }^{\circ} \mathrm{C}\right)$ & $\Delta \mathrm{h}(\mathrm{J} / \mathrm{g})$ \\
\hline Blending & -5.04 & 5.31 & 10.26 & -10.50 & -5.65 & -4.18 & -12.46 & 7.79 \\
\hline $\mathrm{SL} 2.0 \mathrm{~g}$ & -4.23 & -1.99 & 1.59 & -1.25 & -1.70 & -6.68 & -10.89 & 4.14 \\
\hline SL $4.5 \mathrm{~g}$ & -4.97 & -3.41 & -1.37 & -0.50 & -2.35 & -7.68 & -13.66 & 4.76 \\
\hline
\end{tabular}


blending products. Moreover, for $4.5 \mathrm{~g}$ of enzyme loading showed a lower melting and a crystallization temperature as compared to that of $2.0 \mathrm{~g}$ enzyme loading.

\section{CONCLUSIONS}

Lipase-catalyzed transesterification reactions can be used to synthesize a potential lipid of MLM type-structured lipid, 1,3-dicapryoyl-2-oleoyl-sn-glycerol (COC, ECN 32). Within this study, the enzyme loadings utilized might be excessive as indicated by little or no effect on the formation of TAGs. Higher residence times (i.e., 30 and $60 \mathrm{~min}$ ) showed to decrease the concentrations of TAGs. This consequently influenced the slip melting point of the transesterified products. Conclusively, in continuous transesterification, residence time $\tau$ of $15 \mathrm{~min}$, and enzyme loading $\left(\mathrm{E}_{0}\right)$ of $2.0 \mathrm{~g}$ were selected as the optimum conditions to obtain the highest productivity for COC formation.

\section{Abbreviations}

\begin{tabular}{|c|c|}
\hline $\mathrm{COC}$ & $\begin{array}{l}\text { : 1,3-dicapryoyl-2-oleoyl-sn-glycerol / } \\
\text { caprylic-oleic-caprylic }\end{array}$ \\
\hline DAG & : Diacylglycerol \\
\hline DSC & : Differential scanning calorimetry \\
\hline $\mathrm{ECN}$ & : Equivalent carbon number \\
\hline FFA & : Fatty acid \\
\hline HPLC & :High-performance liquid chromatography \\
\hline IM & : Immobilized \\
\hline LCFA & : Long chain fatty acid \\
\hline MAG & : Monoacylglycerol \\
\hline MCFA & : Medium chain fatty acid \\
\hline MLM-SL & : Medium-long-medium structured lipid \\
\hline MPL & : Myristic-palmitic-linoleic \\
\hline OLO & : Oleic-linoleic-oleic \\
\hline $\mathrm{OOO}$ & : Oleic-oleic-oleic; \\
\hline PBR & : Packed-bed reactor \\
\hline PLO & : Palmitic-linoleic-oleic \\
\hline PLP & : Palmitic-linoleic-palmitic \\
\hline $\mathrm{POO}$ & : Palmitic-oleic-oleic \\
\hline POP & : Palmitic-oleic-palmitic \\
\hline $\mathrm{RBDO}$ & : Refined bleached deodorized palm olein \\
\hline SL & : Structured lipid \\
\hline SMP & : Slip melting point \\
\hline$s n-$ & : Stereospecific number \\
\hline TAG & : Triacylglycerol \\
\hline $\mathrm{TC} / \mathrm{CCC}$ & : Tricaprylin \\
\hline TD & : Transesterification degree \\
\hline TL & : Thermomyces lanuginosus \\
\hline
\end{tabular}

\section{ACKNOWLEDGEMENTS}

The authors acknowledge the Ministry of Research, Technology and Higher Education of Indonesia for the financial support to the first author through The Master of Education towards Doctoral Scholarship Program for Excellent Undergraduate (PMDSU).

\section{Authors' contributions}

QDU conducted the research, analyzed the data, and drafted the manuscript. ABS, DRA, and PHA supervised the research, reviewed the manuscript, and provided comments to enhance the quality of manuscript. All authors read and approved the final manuscript.

\section{REFERENCES}

AOCS. 2017a. AOCS official method Cd 11b-91. In: Official Methods and Recommended Practices of the AOCS. American Oil Chemist's Society Press, Champaign, IL, USA.

AOCS. 2017b. AOCS official method Cc 3-25. In: Official Methods and Recommended Practices of the AOCS. American Oil Chemist's Society Press, Champaign, IL, USA.

Basri, M., M. A. Kassim, R. Mohamad and A. B. Ariff. 2013. Optimization and kinetic study on the synthesis of palm oil ester using Lipozyme TL im. J. Mol. Catal. B Enzym. 85-86: 214-219.

Basso, R. C., A. P. B. Ribeiro, M. H. Masuchi, L. A. Gioielli, L. A. G. Gonçalves, A. O. dos Santos, L. P. Cardoso and R. Grimaldi. 2010. Tripalmitin and monoacylglycerols as modifiers in the crystallisation of palm oil. Food Chem. 122: 1185-1192.

Hermansyah, H., A. Wijanarko, M. Gozan, P. P. D. Wulan, R. Arbianti, R. W. Soemantojo, T. S. Utami, M. Kubo, N. Shibasaki-Kitakawa and T. Yonemoto. 2010. Kinetic model for triglyceride hydrolysis using lipase: Review. MAKARA Technol. Ser. 11: 30-35.

Holčapek, M., M. Lísa, P. Jandera and N. Kabátová. 2005. Quantitation of triacylglycerols in plant oils using HPLC with APCI-MS, evaporative light-scattering, and UV detection. J. Sep. Sci. 28: 1315-1333.

Itabaiana, I., L. S. De Mariz E Miranda and R. O. M. De Souza. 2013. Towards a continuous flow environment for lipase-catalyzed reactions. J. Mol. Catal. B Enzym. 85-86: 1-9.

Kadhum, A. A. H. and M. N. Shamma. 2017. Edible lipids modification processes: A review. Crit. Rev. Food Sci. Nutr. 57: 48-58.

Lai, O. M., C. T. Low and C. C. Akoh. 2005. Lipase-catalyzed acidolysis of palm olein and caprylic acid in a continuous benchscale packed bed bioreactor. Food Chem. 92: 527-533.

Levenspiel, O. 1999. Chemical Reaction Engineering. $3^{\text {rd }}$ ed. John Wiley \& Sons, Inc., New York.

May, C. Y. and K. Nesaretnam. 2014. Research advancements in palm oil nutrition. Eur. J. Lipid Sci. Technol. 116: 1301-1315.

Mele, M. A., M. Z. Islam, H. M. Kang and A. M. Giuffrè. 2018. Preand post-harvest factors and their impact on oil composition and quality of olive fruit. Emirates J. Food Agric. 30: 592-603.

Ong, A. S. H. and S. H. Goh. 2002. Palm oil: A healthful and cost effective dietary component. Food Nutr. Bull. 23: 11-22.

Saberi, A. H., C. P. Tan and O. M. Lai. 2011. Phase behavior of palm oil in blends with palm-based diacylglycerol. J. Am. Oil Chem. Soc. 88: 1857-1865.

Siew, W. L. 2002. Understanding the interactions of diacylglycerols with oils for better product performance. Palm. Oil Dev. 36: 6-12.

Silva, R. C., F. A. S. De Martini Soares, T. G. Fernandes, A. L. D. Castells, K. C. G. Da Silva, M. I. A. Gonçalves, C. C. Ming, L. A. G. Gonçalves 
and L. A. Gioielli. 2011. Interesterification of lard and soybean oil blends catalyzed by immobilized lipase in a continuous packed bed reactor. J. Am. Oil Chem. Soc. 88: 1925-1933.

Sitanggang, A. B., A. Drews and M. Kraume. 2014a. Continuous synthesis of lactulose in an enzymatic membrane reactor reduces lactulose secondary hydrolysis. Bioresour. Technol. 167: 108-115.

Sitanggang, A. B., A. Drews and M. Kraume. 2014b. Rapid transgalactosylation towards lactulose synthesis in a small-scale enzymatic membrane reactor (EMR). Chem. Eng. Trans. 38: 19-24.

Sitanggang, A. B., A. Drews and M. Kraume. 2015. Influences of operating conditions on continuous lactulose synthesis in an enzymatic membrane reactor system: A basis prior to long-term operation. J. Biotechnol. 203: 89-96.

Sitanggang, A. B., A. Drews and M. Kraume. 2016. Development of a continuous membrane reactor process for enzyme-catalyzed lactulose synthesis. Biochem. Eng. J. 109: 65-80.

Subroto, E., T. Utami and C. Hidayat. 2019. Enzymatic glycerolysisinteresterification of palm stearin-olein blend for synthesis structured lipid containing high mono-and diacylglycerol. Food Sci. Biotechnol. 28: 511-517.

Utama, Q. D., A. B. Sitanggang, D. R. Adawiyah and P. Hariyadi. 2019. Lipase-catalyzed interesterification for the synthesis of medium-long-medium (MLM) structured lipids-a review. Food Technol. Biotechnol. 57: 305-318.
Utama, Q. D., A. B. Sitanggang, D. R. Adawiyah and P. Hariyadi. 2020. Lipase-catalyzed synthesis of medium-long-medium-type of structured lipids from refined bleached deodorized olein. Appl. Food Biotechnol. 7: 85-94.

Vandenberghe, C., V. St-Pierre, T. Pierotti, M. Fortier, C. A. Castellano and S. C. Cunnane. 2017. Tricaprylin alone increases plasma ketone response more than coconut oil or other medium-chain triglycerides : An acute crossover study in healthy adults. Curr. Dev. Nutr. 1: 1-5.

Wang, Y., H. Wu and M. H. Zong. 2008. Improvement of biodiesel production by lipozyme TL IM-catalyzed methanolysis using response surface methodology and acyl migration enhancer. Bioresour. Technol. 99: 7232-7237.

Xu, X., T. Porsgaard, H. Zhang, J. Adler-Nissen and C. E. Høy. 2002. Production of structured lipids in a packed-bed reactor with Thermomyces lanuginosa lipase. J. Am. Oil Chem. Soc. 79: 561-565.

Yang, H., Y. Mu, H. Chen, C. Su, T. Yang and Z. Xiu. 2014. Sn-1,3specific interesterification of soybean oil with medium-chain triacylglycerol catalyzed by Lipozyme TL IM. Chinese J. Chem. Eng. 22: 1016-1020.

Zhang, H., X. Xu, J. Nilsson, H. Mu, J.Adler-Nissen and C. E. Høy. 2001. Production of margarine fats by enzymatic interesterification with silica-granulated Thermomyces lanuginosa lipase in a large-scale study. J. Am. Oil Chem. Soc. 78: 57-64. 